\title{
Efficacy of Local Therapy for Oligometastatic Hepatocellular Carcinoma: A Propensity Score Matched Analysis
}

This article was published in the following Dove Press journal: Journal of Hepatocellular Carcinoma

\author{
Kangpyo Kim' \\ Tae Hyung Kim (D) ${ }^{\prime}$ \\ Tae Hyun Kim² \\ Jinsil Seong $\mathbb{D}^{\prime}$
}

'Department of Radiation Oncology, Yonsei University College of Medicine, Seoul, Republic of Korea; ${ }^{2}$ Department of Statistics, University of Chicago, Chicago, IL, USA
Correspondence: Jinsil Seong Department of Radiation Oncology, Yonsei University College of Medicine, Seoul, 03722, Republic of Korea

Tel $+82-2-2228-8 I I I$

$\mathrm{Fax}+82-2-2227-7823$

Email jsseong@yuhs.ac
Purpose: With respect to various solid cancers, patients with oligometastasis may benefit from local therapy. However, this approach is not widely accepted for hepatocellular carcinoma. This study investigated the efficacy of local therapy for oligometastatic lesions in patients with hepatocellular carcinoma.

Patients and Methods: The study included 69 hepatocellular carcinoma patients presenting with oligometastasis to the lung. Characteristics of the patients and treatment options for metastatic lesions were reviewed, and a survival analysis was performed. After propensity score matching, overall survival and progression-free survival were calculated from the time of pulmonary metastasis detection. Factors predicting prognosis were analyzed using a multivariate Cox regression analysis.

Results: After propensity score matching, 58 patients with Child-Pugh grade A disease were selected. Among them, 22 patients were treated with systemic therapy alone while 36 patients received local therapy or a combination of local and systemic therapies for metastatic lesions. Survival rates were higher in patients receiving local therapy than in those receiving systemic therapy (2-year overall survival rate, 66.6 vs $31.2 \%$, p $<0.001$; 2-year progression-free survival rate, 47.0 vs $10.6 \%, \mathrm{p}=0.005$ ). In the multivariate Cox regression analysis, alpha-fetoprotein levels less than $400 \mathrm{ng} / \mathrm{mL}$ and the use of local therapy for metastatic lesions were found to be significant favorable prognostic factors.

Conclusion: Local therapy for metastatic lesions improved the oncologic outcomes of patients with hepatocellular carcinoma with pulmonary oligometastasis.

Keywords: HCC, local ablation therapy, oligometastasis, propensity score matching

\section{Introduction}

The concept of oligometastasis, a transition point between localized disease and widespread metastasis, is widely accepted for many types of solid tumors. ${ }^{1}$ According to this concept, better outcomes can be anticipated with aggressive local intervention, such as surgical resection or radiotherapy for the limited metastatic lesions, potentially halting the development of polymetastatic disease. $^{2}$ For decades, hepatic resection for metastatic colorectal cancer has been recognized as a standard treatment option; furthermore, local consolidative therapy (LCT) for oligometastases from non-small cell lung cancer has shown promising results in a randomized Phase II study. ${ }^{3,4}$ However, for hepatocellular carcinoma (HCC), systemic treatment is the standard of care, regardless of metastatic status. 5,6 
This study intended to answer the question of whether the concept of oligometastasis can be applied to HCC. For better patient homogeneity, patients presenting with single-organ pulmonary oligometastasis were included in this study. The lungs were chosen as the site of metastasis because pulmonary metastasis is the most frequent type of extrahepatic metastasis from $\mathrm{HCC}$, accounting for $18-55 \%$ of cases; furthermore, counting the number of pulmonary metastatic lesions using imaging studies is easier than counting the number of metastases to other organs such as the bone, peritoneum, and lymph nodes. ${ }^{7,8}$ Until now, no studies have completely addressed the prognostic factors for oligometastatic HCC and the survival benefits from local intervention. In this study, we retrospectively analyzed a cohort of HCC patients with single-organ pulmonary metastasis to determine whether local therapy for metastatic pulmonary lesions confers survival benefits. Propensity score matching (PSM) analysis was carried out to compensate for biases owing to the retrospective nature of the study.

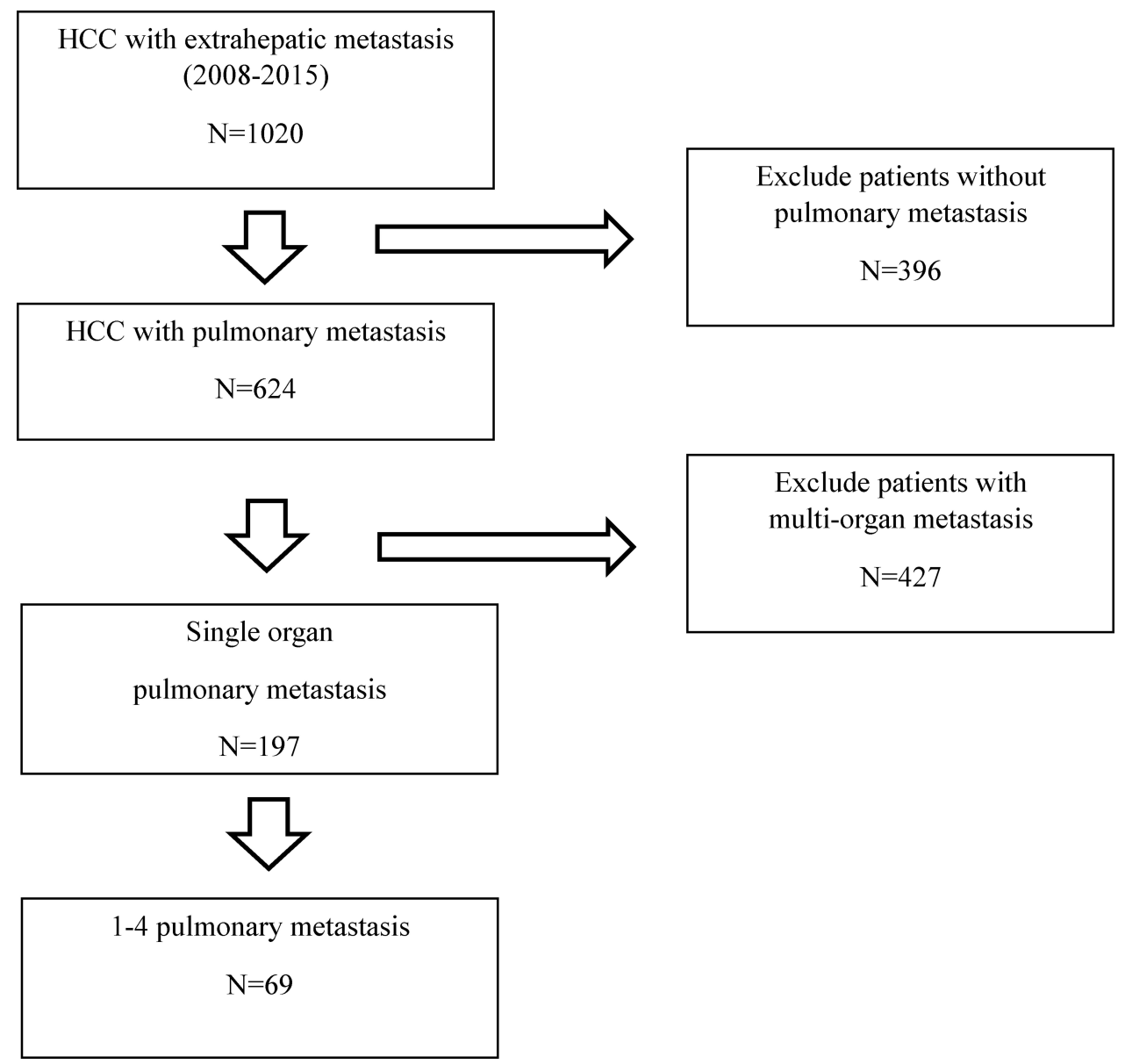

Exclude patients with $\mathrm{N}=427$

\section{Patients and Methods}

\section{Study Population}

We identified $624 \mathrm{HCC}$ patients presenting with pulmonary metastasis from 2008 to 2015 from the Yonsei Cancer Center registry. Among them, 69 patients with 1-4 pulmonary metastases were analyzed (Figure 1). We included patients regardless of the time of development of pulmonary metastasis; some metastases occurred synchronously while some occurred metachronously. We defined synchronous metastasis as pulmonary metastasis found within 1 month of diagnosis of HCC while others are metachronous. The diagnosis of metastasis and its extent was performed based on the results of imaging studies on a symptomatic basis: chest computed tomography (CT), abdominal CT, whole body bone scan, and brain $\mathrm{CT} /$ magnetic resonance imaging (MRI). Patients were divided into two groups: the STx group (systemic therapy alone group) and the LTx group (local therapy group). Patients who were treated with a combination of systemic agents and local therapy were included in the LTx group.

Figure I Flowchart of patient selection. 


\section{Treatment, Response Evaluation, and Toxicity}

A multidisciplinary team at our institution discussed the optimal treatment strategy for advanced HCC and suggested local treatments for viable liver tumors and metastatic lesions according to a patient's condition and disease status. Metastatic pulmonary lesions were surgically resected when complete removal of the metastases seemed possible.

Imaging studies, including abdominal CT and liver MRI, were performed every 2-3 months to detect intrahepatic lesions. Based on the CT and MRI findings, treatment responses were evaluated according to Response Evaluation Criteria in Solid Tumors criteria; ${ }^{9}$ for the evaluation of complete remission in intrahepatic lesions, modified RECIST criteria was used. ${ }^{10}$ In our study, the progression of either a viable liver lesion or pulmonary metastasis was considered to indicate progressive disease. Metastatic pulmonary lesions were evaluated using chest CT every $2-3$ months after treatment; ${ }^{18} \mathrm{~F}$-fluorodeoxyglucose positron emission tomography-CT was performed according to clinical needs. Treatment-related toxicities at the time of follow-up were graded according to the Common Terminology Criteria for Adverse Events (version 4.03). ${ }^{11}$

\section{Statistical Analysis and Propensity Score Matching}

Statistical analyses were performed using SPSS version 23 (SPSS, Chicago, IL, USA) and R (version 3.6.1; R Development Core Team 2009, Vienna, Austria). P-values $<0.05$ were considered significant. The primary endpoint was overall survival (OS), defined as the interval from the date of diagnosis of pulmonary metastasis to the date of death from any cause or to the date of the last visit. Progression-free survival (PFS) was calculated from the initiation of local or systemic therapy for metastatic lesions to the first detection of disease progression on CT or MRI. Patients who died before their first radiologic assessment post-treatment were considered to have progressive disease. The cumulative survival probability was calculated using the Kaplan-Meier method, and survival curves were compared using the Log rank test. Patients lost to follow-up were censored at the date of the last visit. To minimize selection bias and the effects of potential confounders, patients were matched based on propensity scores. PSM analysis was performed using the MatchIt package $^{12}$ in R. Propensity scores were calculated based on age, sex, Child-Pugh grade, liver cirrhosis, control of the primary liver lesion, serum alpha-fetoprotein (AFP) levels, and prothrombin induced by vitamin $\mathrm{K}$ absence-II (PIVKAII) levels using a multivariate logistic regression model. Patients with the exact same scores (exact score matching method) were matched, and non-matched patients were excluded. Univariate and multivariate Cox proportional regression analyses were performed to determine the hazard ratios (HRs) for potential prognostic factors.

\section{Results}

\section{Patient Characteristics}

Patient characteristics at the time of detection of pulmonary metastasis are summarized in Table 1 . There were 36 patients who received local therapy and 33 patients who received systemic therapy alone. Male B-viral HCCs were the most common. Liver cirrhosis was more frequent in the STx group than in the LTx group (75.8 vs $41.2 \%$ ). In the STx group, onethird of patients showed Child-Pugh grade B liver function, while all 36 patients in the LTx group showed Child-Pugh grade A liver function. PSM was carried out to compensate for these differences. After PSM, most features including ChildPugh grade, control of the primary liver lesion, liver cirrhosis, and AFP levels were well balanced in the patients.

\section{Treatment and Survival Outcomes After PSM}

The treatment details for all patients are summarized in Table 2. In the LTx group, 16 patients underwent surgical resection and 12 patients received radiotherapy for metastatic lesions. Prescribed radiation doses for metastatic pulmonary lesions are as follows; 50 Grays (Gy)/10 fractions ( $\mathrm{fx}$ ) for 6 patients, $50 \mathrm{~Gy} / 5 \mathrm{fx}$ for 3 patients, $60 \mathrm{~Gy} / 4$ fx for 2 patients and $40 \mathrm{~Gy} / 16 \mathrm{fx}$ for 1 patient. Eight patients in the LTx group were treated with combination therapy (local therapy + systemic therapy).

The median follow-up period was 27 (interquartile range, 19.0-36.7) months in the LTx group and 23 (interquartile range, 14.0-31.3) months in the STx group. The 1-year and 2-year OS rates were $88.5 \%$ and $66.6 \%$ in the LTx group and $63.6 \%$ and $31.2 \%$ in the STx group, respectively $(\mathrm{p}<0.001$; Figure 2A). The 1-year and 2-year PFS rates were 58.9\% and $47.0 \%$ in the LTx group and $21.2 \%$ and $10.6 \%$ in the STx group, respectively ( $\mathrm{p}=0.005$; Figure $2 \mathrm{~B}$ ). Figure 3 demonstrates survival curves according to the number of pulmonary metastases. Local therapy was found to confer a survival benefit when patients with 2 pulmonary metastases are included in the survival analysis (Figure 3A and B). The 2-year OS rate in patients with only 1 pulmonary metastasis was $70.7 \%$ in the 
Table I Patient Characteristics at the Time of Detection of Lung Metastasis Before and After PSM in the LTx and STx Groups

\begin{tabular}{|c|c|c|c|c|c|c|}
\hline \multirow[t]{2}{*}{ Variables } & \multicolumn{3}{|c|}{ Before PSM } & \multicolumn{3}{|c|}{ After PSM } \\
\hline & LTx $(n=36)$ & STx $(n=33)$ & P-value & $\operatorname{LTx}(n=36)$ & STx $(n=22)$ & P-value \\
\hline Age, years (median, range) & $57(35-75)$ & $51(34-76)$ & 0.174 & $57(35-75)$ & $50(38-76)$ & 0.136 \\
\hline Sex n, (\%) & & & 0.22 & & & 0.11 \\
\hline M & $29(80.6)$ & $30(90.9)$ & & $29(80.6)$ & $21(95.5)$ & \\
\hline $\mathrm{F}$ & $7(19.4)$ & $3(9.1)$ & & $7(19.4)$ & I (4.5) & \\
\hline HCC etiology & & & 0.104 & & & $0.41 \mathrm{I}$ \\
\hline B-viral & $26(72.2)$ & $25(75.8)$ & & $26(72.2)$ & $18(81.8)$ & \\
\hline C-viral & $2(5.6)$ & $4(12.1)$ & & $2(5.6)$ & $2(9.1)$ & \\
\hline Others & $8(22.2)$ & $4(12.1)$ & & $8(22.2)$ & $2(9.1)$ & \\
\hline Control of the primary liver lesion, $n$ (\%) & & & 0.024 & & & 0.304 \\
\hline CR & $18(50.0)$ & $10(30.3)$ & & $18(50.0)$ & $10(45.5)$ & \\
\hline PR & II (30.6) & $5(15.2)$ & & II (30.6) & $4(18.2)$ & \\
\hline SD & $0(0.0)$ & $4(12.1)$ & & $0(0.0)$ & $0(0.0)$ & \\
\hline PD & $7(19.4)$ & $13(39.4)$ & & $7(19.4)$ & $8(36.4)$ & \\
\hline Unevaluable or unknown & $0(0.0)$ & I (3.0) & & $0(0.0)$ & $0(0.0)$ & \\
\hline Liver cirrhosis, n (\%) & & & 0.015 & & & 0.119 \\
\hline Yes & $17(47.2)$ & $25(75.8)$ & & $17(47.2)$ & $15(68.2)$ & \\
\hline No & $19(52.8)$ & $8(24.2)$ & & $19(52.8)$ & $7(31.8)$ & \\
\hline $\mathrm{CP}$ grade, $\mathrm{n}(\%)$ & & & $<0.001$ & & & $N / A$ \\
\hline A & $36(100)$ & $22(66.7)$ & & $36(100)$ & $22(100)$ & \\
\hline B & $0(0.0)$ & II (33.3) & & $0(0.0)$ & $0(0.0)$ & \\
\hline C & $0(0.0)$ & $0(0.0)$ & & $0(0.0)$ & $0(0.0)$ & \\
\hline Development time of metastasis, $n(\%)$ & & & 0.716 & & & $0.58 \mathrm{I}$ \\
\hline Synchronous & $3(8.3)$ & $2(6.1)$ & & $3(8.3)$ & I (4.5) & \\
\hline Metachronous & $33(91.7)$ & $31(93.9)$ & & $33(91.7)$ & $21(95.5)$ & \\
\hline Tumor markers & & & & & & \\
\hline AFP, ng/mL (median, mean, range) & $\begin{array}{c}40.94,333.80 \\
1.92-3407.63\end{array}$ & $\begin{array}{c}454.73,5208.70 \\
1.9-49,317.4\end{array}$ & 0.028 & $\begin{array}{c}40.94,333.80 \\
1.92-3407.63\end{array}$ & $\begin{array}{c}221.67,553.42 \\
1.90-3586.4\end{array}$ & 0.34 \\
\hline PIVKA II, mAU/mL (median, mean, range) & $\begin{array}{c}127.6,616.62 \\
14-84 \mid 4\end{array}$ & $\begin{array}{c}165.60,3010.24 \\
15-75,000\end{array}$ & 0.292 & $\begin{array}{c}\text { 127.6. 616.62, } \\
|4-84| 4\end{array}$ & $\begin{array}{c}85.2,283.62 \\
15-2000\end{array}$ & 0.399 \\
\hline $\begin{array}{l}\text { Time interval between the initial HCC diagnosis } \\
\text { and extrahepatic metastasis development, months } \\
\text { (median, range) }\end{array}$ & $23(0-73)$ & $19(0-61)$ & 0.042 & $23(0-73)$ & $24(2-6 I)$ & 0.276 \\
\hline
\end{tabular}

Abbreviations: PSM, propensity score matching; LTx, local therapy; STx, systemic therapy alone; HCC, hepatocellular carcinoma; CR, complete response; PR, partial response; SD, stable disease; PD, progressive disease; CP, Child Pugh; AFP, alpha-fetoprotein; PIVKA-II, protein induced by vitamin K absence of antagonist II.

LTx group and $0 \%$ in the STx group $(\mathrm{p}<0.001)$; the corresponding 2-year PFS rate was 49.7 in the LTx group and $0 \%$ in the $\mathrm{STx}$ group $(\mathrm{p}=0.009)$ (Figure $3 \mathrm{C}$ and $\mathrm{D})$.

\section{Prognostic Factors Affecting OS and PS After PSM (Table 3)}

To identify the possible prognostic factors, univariate and multivariate analysis were performed for median age ( $<53$ vs $\geq 53$ years), control of the primary liver lesion (complete remission/partial response vs progressive disease), liver cirrhosis (yes or no), application of local therapy for metastatic lesions (yes or no), and serum levels of AFP ( $<400 \mathrm{vs} \geq 400 \mathrm{ng} /$ $\mathrm{mL}$ ) and PIVKA-II ( $<200 \mathrm{vs} \geq 200 \mathrm{mAU} / \mathrm{mL}$ ). To minimize the bias, separate sets of analysis were carried out according to the number of pulmonary lesions. Multivariate analysis identified AFP levels $<400 \mathrm{ng} / \mathrm{mL}$ and the application of local therapy as prognostic factors for a better OS, with HRs of 4.366 and 3.574, respectively. These factors remained 
Table 2 Treatment Options for Metastatic Lung Lesions

\begin{tabular}{|l|c|c|}
\hline \multirow{2}{*}{ Treatment Options } & \multicolumn{2}{|c|}{ Number of Patients (\%) } \\
\cline { 2 - 3 } & Before PSM & After PSM \\
\hline Sorafenib or cytotoxic chemotherapy alone & $33(47.8)$ & $22(37.9)$ \\
Surgery & $16(23.2)$ & $16(27.6)$ \\
Radiotherapy & $12(17.4)$ & $12(20.7)$ \\
Local therapy* + systemic therapy** & $8(11.6)$ & $8(13.8)$ \\
\hline
\end{tabular}

Notes: *Surgery or radiotherapy. **Sorafenib or cytotoxic chemotherapy (5-FU +cisplatin, 5-FU+adriamycin+cytoxan, or tegafur + 5-FU).

Abbreviation: PSM, propensity score matching.

significant in the analysis of patients with 1 or 2 pulmonary lesions. In analysis for PFS, both the application of local therapy and AFP levels $<400 \mathrm{ng} / \mathrm{mL}$ were also shown to be a significant prognostic factors, with an HR of $3.992(p=0.018)$ and $2.243(p=0.036)$ respectively. Local therapy for metastatic lesions remained significant in the analysis of patients with 1 pulmonary lesion (Supplementary Table 1).

\section{Toxicity}

Local therapy-related toxicity was observed in 10 patients (27.8\%). Complications included esophagitis $(\mathrm{n}=5)$, cough $(\mathrm{n}=3)$, fatigue $(\mathrm{n}=3)$, pneumonitis $(\mathrm{n}=3)$, nausea and vomiting $(n=2)$, pleural effusion $(n=1)$, and fever $(n=1)$. One patient experienced grade 3 pneumonitis with pleural effusion after undergoing surgical removal of the metastatic lesions but recovered from the toxicities without lethality. After radiation therapy, 2 patients showed grade 2 adverse events: 1 patient had grade 2 nausea, vomiting, and cough and 1 patient had grade 2 pneumonitis and cough.

During and after systemic therapy, 23 patients (76.7\%) suffered from treatment related toxicities. Sorafenib induced skin and subcutaneous tissue disorders appeared in 17 patients of which 12 cases were grade 2 or worse. Four patients were ceased to use sorafenib due to skin complications.

Thrombocytopenia after cytotoxic chemotherapy was observed for 4 patients; 2 patients each for grade 2 and grade 3. Other complications were fatigue $(n=3)$, diarrhea $(\mathrm{n}=3)$, nausea and vomiting $(\mathrm{n}=2)$, neutropenia $(\mathrm{n}=1)$. All grade 1 or 2 toxicities from local therapy and systemic therapy were self-limiting.

\section{Discussion/Conclusion}

In our study, local therapy for pulmonary metastases from HCC improved the patients' OS and PFS when they had 1-4 pulmonary metastases. Serum AFP levels $<400 \mathrm{ng} / \mathrm{mL}$

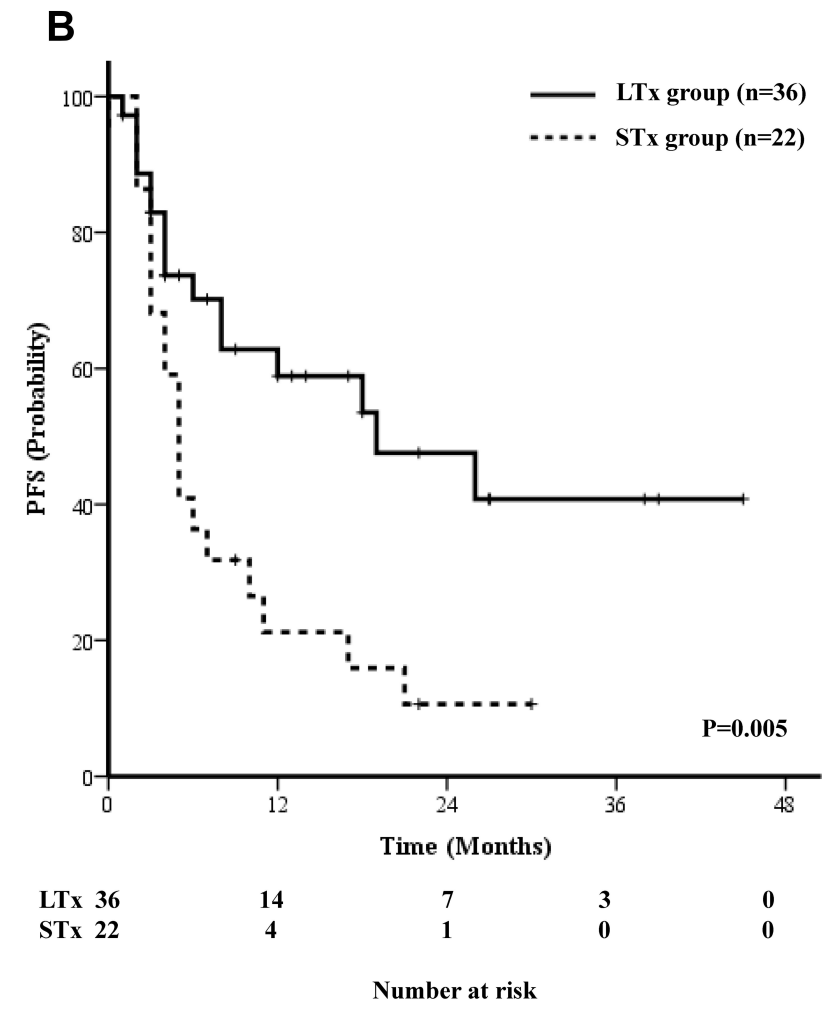

A

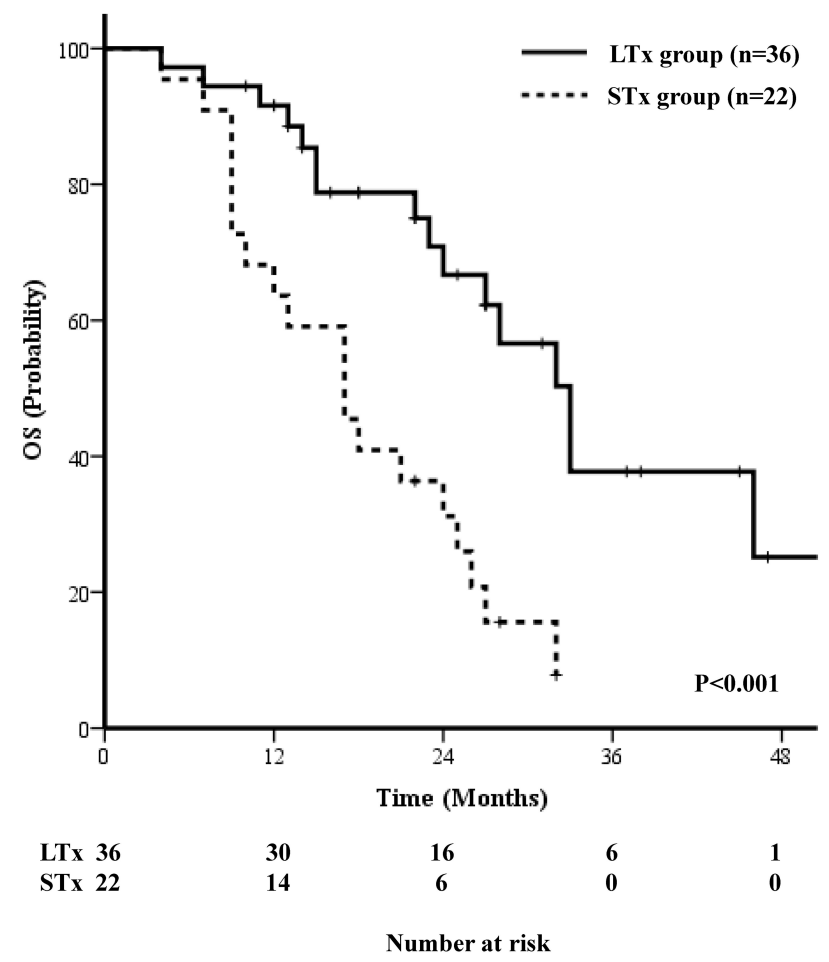

Figure 2 Oncologic outcome in overall survival (A) and progression-free survival (B) according to treatment options for pulmonary metastasis. Abbreviations: OS, overall survival; PFS, progression-free survival; STx, systemic therapy alone; LTx, local therapy. 
A

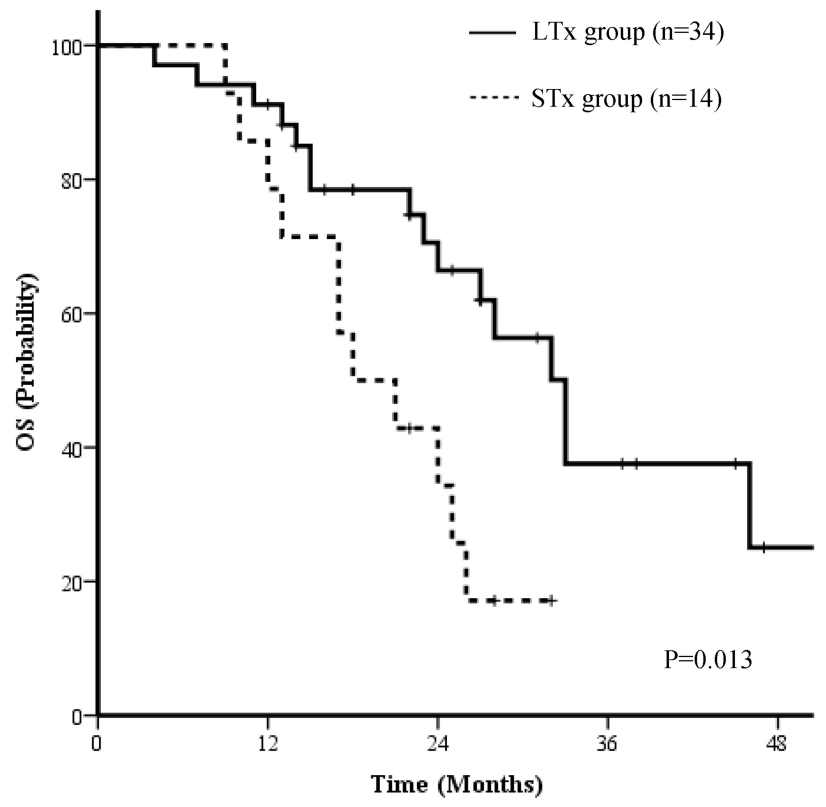

\section{B}

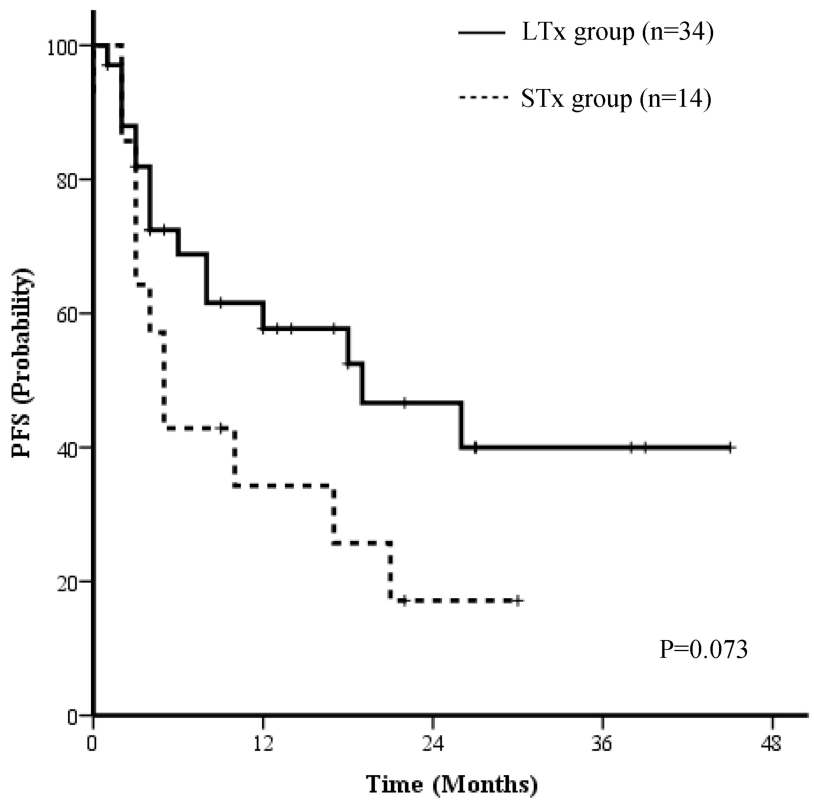

\begin{tabular}{|c|c|c|c|}
\hline LTx 34 & 30 & 16 & 6 \\
\hline STx 14 & 11 & 4 & 0 \\
\hline
\end{tabular}

Number at risk

\section{C}

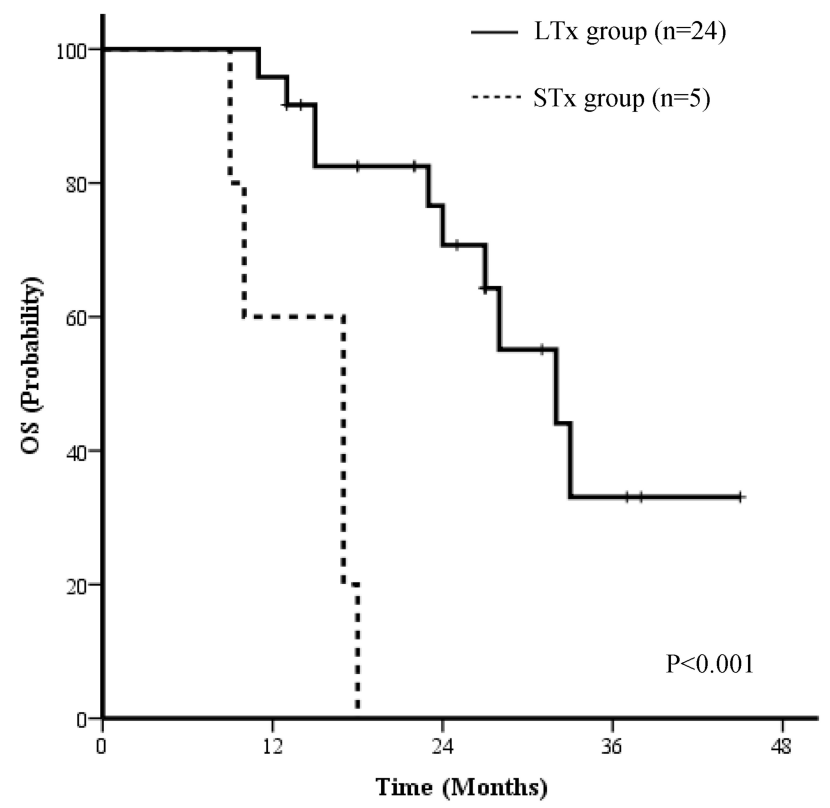

LTx 24

STx 5

23
3

$\begin{array}{lll}12 & 3 & 0 \\ 0 & 0 & 0\end{array}$

Number at risk

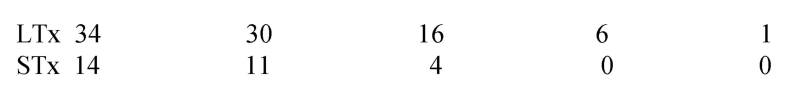

Number at risk

D

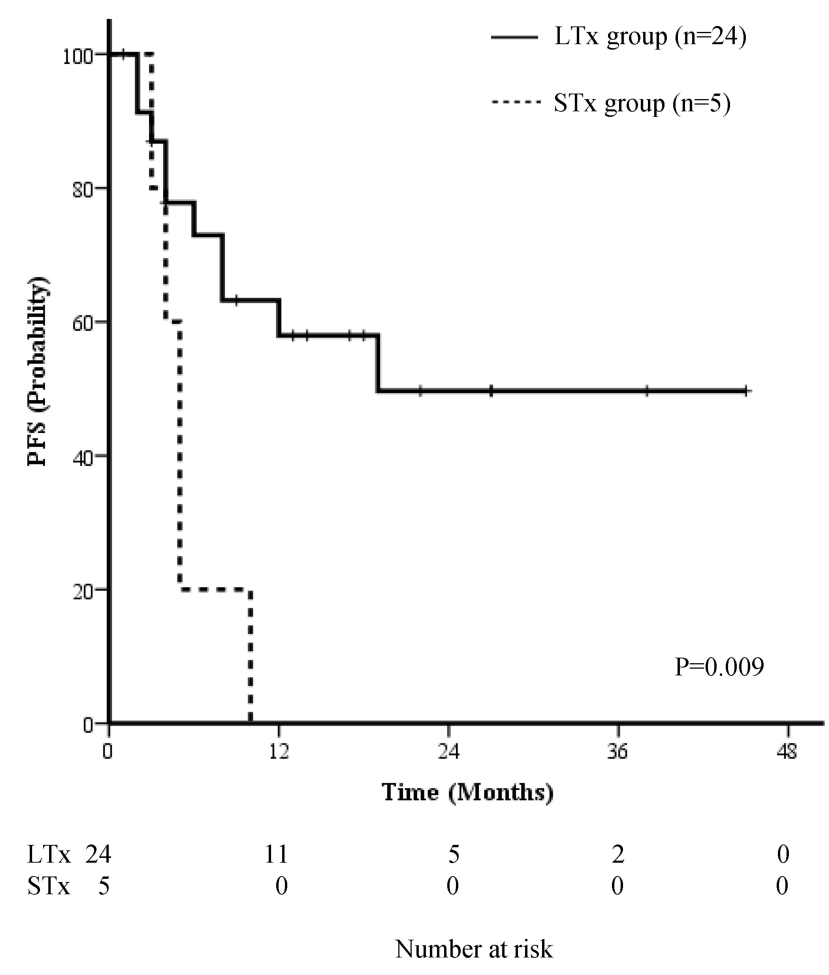

Figure 3 Subgroup analysis of patients by number of metastasis; overall survival, progression free survival in patients with I and 2 metastases (A and B) and within I metastasis (C and $\mathbf{D}$ ).

Abbreviations: OS, overall survival; PFS, progression-free survival; STx, systemic therapy alone; LTx, local therapy. 
Table 3 Prognostic Factors for Overall Survival and Progression-Free Survival After PSM ( $n=58)$

\begin{tabular}{|c|c|c|c|c|c|c|}
\hline \multirow[t]{2}{*}{ Overall Survival } & \multicolumn{3}{|c|}{ Univariate Analysis } & \multicolumn{3}{|c|}{ Multivariate Analysis } \\
\hline & HR & $95 \% \mathrm{Cl}$ & P-value & HR & $95 \% \mathrm{Cl}$ & P-value \\
\hline Age ( $<53$ vs $\geq 53$ years) & 0.914 & $0.411-2.032$ & 0.825 & 1.449 & $0.614-3.420$ & 0.507 \\
\hline Control of the primary liver lesion (CR/PR vs PD) & 1.633 & $0.747-3.568$ & 0.219 & 0.836 & $0.358-1.951$ & 0.615 \\
\hline Liver cirrhosis (yes or no) & 0.644 & $0.326-1.272$ & 0.205 & 0.517 & $0.226-1.187$ & 0.428 \\
\hline Application of local therapy for metastatic lesions & 3.563 & I.734-7.322 & 0.001 & 3.574 & I.703-7.502 & 0.001 \\
\hline AFP (<400 vs $\geq 400 \mathrm{ng} / \mathrm{mL})$ & 4.027 & $1.969-8.237$ & $<0.001$ & 4.366 & $2.058-9.265$ & $<0.001$ \\
\hline PIVKA II (<200 vs $\geq 200 \mathrm{mAU} / \mathrm{mL})$ & 0.918 & $0.456-1.849$ & 0.812 & 0.441 & $0.189-1.031$ & 0.157 \\
\hline \multirow[t]{2}{*}{ Progression-Free Survival } & \multicolumn{3}{|c|}{ Univariate Analysis } & \multicolumn{3}{|c|}{ Multivariate Analysis } \\
\hline & HR & $95 \% \mathrm{Cl}$ & P-value & HR & $95 \% \mathrm{Cl}$ & P-value \\
\hline Age ( $<53$ vs $\geq 53$ years) & 0.622 & $0.282-1.374$ & 0.240 & 0.627 & $0.104-3.764$ & 0.233 \\
\hline Control of the primary liver lesion (CR/PR vs PD) & 1.149 & $0.534-2.471$ & 0.722 & 0.629 & $0.085-4.659$ & 0.864 \\
\hline Liver cirrhosis (yes or no) & 0.647 & $0.329-1.274$ & 0.208 & 0.897 & $0.243-3.312$ & 0.902 \\
\hline Application of local therapy for metastatic lesions & 2.531 & $1.290-4.964$ & 0.007 & 3.992 & $1.266-12.595$ & 0.018 \\
\hline $\operatorname{AFP}(<400$ vs $\geq 400 \mathrm{ng} / \mathrm{mL})$ & 2.806 & $1.368-5.758$ & 0.005 & 2.243 & $1.055-4.767$ & 0.036 \\
\hline PIVKA II (<200 vs $\geq 200 \mathrm{mAU} / \mathrm{mL})$ & 1.104 & $0.549-2.223$ & 0.781 & 0.318 & $0.048-2.086$ & 0.954 \\
\hline
\end{tabular}

Abbreviations: PSM, propensity score matching; CR, complete response; PR, partial response; PD, progressive disease; AFP, alpha-fetoprotein; PIVKA-II, protein induced by Vitamin $\mathrm{K}$ absence of antagonist II; HR, hazard ratio; $\mathrm{Cl}$, confidence interval.

and the use of local therapy for pulmonary metastases were significant favorable prognostic factors for OS and PFS. Only 3 patients experienced grade 2 or worse toxicities in relation to surgical resection or radiotherapy for the pulmonary lesions, without any lethal side effects.

Oligometastasis is a distinctive state of cancer spread, and it has been recognized that local ablative therapies, such as radiotherapy and surgical resection, can be curative options for oligometastatic lesions in various types of solid malignancies. For colorectal cancer, hepatic metastasectomy with curative intent resulted in 10-year survival rates of $20 \%-26 \%$. Local therapy for oligometastases from non-small cell lung cancer increased the time to the appearance of new lesions (median duration: 11.9 months in the local therapy group vs 5.7 months in the maintenance systemic treatment/observation group). ${ }^{3,4}$ However, for $\mathrm{HCC}$, only a few studies have reported favorable treatment results after metastasectomy for oligometastases (Table 4). ${ }^{13-18}$ The major limitation of those studies was selection bias, resulting from the small number of patients and retrospective study design. Additionally, it is still unclear whether local therapy is a preferable method for dealing with oligometastatic HCC as no studies exist when oligometastatic $\mathrm{HCC}$ is treated with systemic therapy alone. To the best of our knowledge, this is the first oligometastatic HCC-related study to involve the following aspects: first, selection bias was compensated through PSM; and second, this study reported favorable treatment

Table 4 Studies Reporting the Outcomes of Metastasectomy for Oligometastatic Hepatocellular Carcinoma

\begin{tabular}{|c|c|c|c|c|c|c|c|c|}
\hline First Author & Publication & Patients & $\begin{array}{l}\text { Treatment for the } \\
\text { Primary Tumor }\end{array}$ & $\begin{array}{l}\text { Organ of } \\
\text { Extrahepatic } \\
\text { Metastasis }\end{array}$ & $\begin{array}{l}\text { Treatment for } \\
\text { Metastatic } \\
\text { Tumors }\end{array}$ & $\begin{array}{l}\text { Median } \\
\text { Disease-Free } \\
\text { Interval } \\
\text { (Months) }\end{array}$ & $\begin{array}{l}\text { No. of Lesions } \\
\text { (\%) }\end{array}$ & $\begin{array}{l}\text { Survival After } \\
\text { Metastasectomy } \\
\text { (Months) }\end{array}$ \\
\hline Zhu [13] & 2013 & 18 & Resection (100\%) & Lung & Resection (100\%) & NR & I (100\%) & $5-y r: 61.1$ \\
\hline Chen [14] & 2008 & 12 & $\begin{array}{l}\text { Resection }(83 \%) / \\
\text { Transplantation (17\%) }\end{array}$ & Lung & Resection (100\%) & 12 & I (75\%)/2 (25\%) & $5-y r: 30$ \\
\hline Tomimaru [15] & 2006 & 8 & Resection (100\%) & Lung & Resection (100\%) & 32 & I (50\%)/2 (50\%) & $5-y r: 58$ \\
\hline Lam [16] & 1998 & 9 & NR & Lung & Resection (100\%) & NR & I (100\%) & 5-yr: 67 \\
\hline Kobayashi [17] & 2011 & 18 & NR & Regional lymph node & Resection (100\%) & 36 & I (100\%) & Median: 29 \\
\hline Park [18] & 2007 & 5 & $\begin{array}{l}\text { Resection/TACE/ } \\
\text { Chemotherapy }\end{array}$ & Adrenal gland & Resection (100\%) & $N R$ & I (100\%) & Median: 21 \\
\hline
\end{tabular}


results with local therapy compared to those with systemic therapy alone.

One hypothesis that explains the better treatment results in patients with oligometastases has been reported. In 2018, Weichselbaum commented that oligometastatic status might be defined not only by the number of metastases but also by the overall tumor burden, time to metastasis, pace of tumor progression, molecular composition of the tumor, and host response to metastasis. ${ }^{19}$ In colorectal cancer, the oligometastatic profile depends on biological drivers such as microRNAs rather than the disease status at diagnosis or therapeutic interventions. ${ }^{20}$ Signature patterns of microRNAs are potential markers in non-smallcell lung carcinomas that can be used to distinguish the prognosis of patients, even though molecular evidence of oligometastasis in non-small-cell lung carcinomas is not well understood. ${ }^{21}$ However, it is difficult to find studies about oligometastatic biomarkers, genetic or clinical prognostic factors, and the relations between molecular characteristics and treatment outcomes with respect to $\mathrm{HCC}$ oligometastasis.

One of the barriers that further restricts clinical or genetic research on extrahepatic oligometastasis is the relative difficulty in controlling the primary cancer. As most patients with advanced HCC die from liver failure rather than from the progression of extrahepatic metastasis, control of the primary lesion can be a vital issue in oligometastatic HCC. Liver-directed regional therapies, such as transarterial chemoembolization, have been reported to prolong the OS of unresectable HCC patients in some studies; however, the potential benefits of these therapies are still controversial with respect to extrahepatic metastasis. According to a study on the Surveillance, Epidemiology, and End Results database, 151 patients received liver-directed local treatment among 2529 patients, and the OS and cancer-specific survival were longer in the liver-directed local therapy group $(p<0.0001){ }^{22}$ The only factor related with better survival was the use of local therapy. Meanwhile, several studies have also reported that the use of transarterial chemoembolization or other aggressive liver-directed therapies is not an independent favorable prognostic factor. ${ }^{23,24} \mathrm{In}$ our study, liver-directed local therapy after the diagnosis of pulmonary metastasis seemed to be beneficial for the patients' survival. Among 30 patients with viable liver tumors, 20 received liver-directed therapy, and the 1-year and 2-year OS rates were $74.0 \%$ and $54.6 \%$, respectively. Those who did not receive liver-directed local therapy showed 1-year and 2-year OS rates of $50.0 \%$ and $20 \%$, respectively $(\mathrm{p}=0.074)$. In terms of tumor burden as one of the factors affecting the state of oligometastasis, liverdirected regional therapies could reduce the overall tumor burden and prolong the OS of oligometastatic HCC patients.

The prognostic factors in patients with extrahepatic metastasis vary across studies. Japanese groups have reported that the presence of an intrahepatic viable lesion and lower performance scores ${ }^{25}$ or Child-Pugh grade B or C, a neutrophil-lymphocyte ratio over 4.0, increased white blood cell count, and advanced primary tumor stage (T4) ${ }^{26}$ were independent prognostic factors. However, the available data are extremely rare with respect to single-organ oligometastasis. An AFP level $\geq 400 \mathrm{ng} / \mathrm{mL}$ was a predictive factor of worse OS in our study. Although the prognostic cut-off value for AFP has not been standardized, an elevated AFP level is an established worse prognostic factor for post-LTx outcomes, ${ }^{27}$ OS rates, ${ }^{28-30}$ recurrence-free survival rates, ${ }^{31,32}$ and an increased probability of extrahepatic recurrence. ${ }^{33}$ As elevated AFP levels increase the likelihood of recurrence, we suggest that a hidden tumor burden might exist in dormancy even after complete removal of the radiologically visible cancer, which is not detected on CT or MRI. The invisible tumors cause metastatic cascades after activation with making genetic variances, spreading malignant cells in multiple intra-extrahepatic sites. This mechanism is consistent with our finding that the median OS was only 10 months in patients with AFP levels $\geq 400 \mathrm{ng} / \mathrm{mL}$. The second prognostic factor in our study was the application of local therapy for metastatic lesions. A large sub-group of the LTx group drew our attention. Among the 36 patients in the LTx group, 28 patients (over 77\%) were treated with surgery or radiotherapy for metastatic lesions as the firstline therapy; the 1-year and 2-year PFS rates for the 28 patients were $62.0 \%$ and $54.3 \%$, respectively. Among 14 patients who had no viable liver lesions, the 5-year survival rate was $57.1 \%$, and 6 patients did not experience any recurrence without further treatment. In the same context, one Korean group reported that pulmonary metastasectomy after LTx resulted in significantly higher 2-year and 5 -year survival rates compared to those in the nonmetastasectomy group ( 30.6 vs $0 \%, \mathrm{p}=0.007$; and 44.7 vs $12.8 \%, \mathrm{p}=0.017$, respectively) with tolerable toxicities. Among 23 patients who were treated with pulmonary metastasectomy, combined therapy with sorafenib was administered to only 4 patients. ${ }^{34}$ 
There are some limitations to our study. Firstly, the sample sizes for the LTx and STx groups were relatively small. Since the number of patients sets which can be an issue for statistical power and appropriateness of analyzing method was small, subgroup analysis according to possible prognostic factors such as treatment method of primary liver cancer was not available. Randomized prospective studies are required to compensate additional biases and confounders which may derive from each patient's detailed characteristics. Second, there may be inconsistencies in the therapies used, and some of these therapies could have been old-fashioned owing to the long period of patient enrollment. Third, the results should be reviewed with caution as this is a retrospective analysis.

In conclusion, this study showed that local therapy improved the oncologic outcomes of patients with a limited number of lung metastases, particularly those with good liver function and AFP levels less than $400 \mathrm{ng} / \mathrm{mL}$. Further studies with a larger number of patients and homogenous treatment modalities are needed to support our data.

\section{Ethics Approval and Informed Consent}

Patients have given their written informed consent and the study protocol was approved by institutional review board of Severance Hospital, Yonsei University (IRB approval No. 4-2020-0872) for the retrospective clinical study. This study was performed in compliance with the Declaration of Helsinki.

\section{Author Contributions}

All authors made substantial contributions to conception and design, acquisition of data, or analysis and interpretation of data; took part in drafting the article or revising it critically for important intellectual content; agreed to submit to the current journal; gave final approval of the version to be published; and agree to be accountable for all aspects of the work.

\section{Funding}

This study was supported by the Dong-A research fund (Grant number: 2018-31-0904).

\section{Disclosure}

The authors have no conflicts of interest to declare.

\section{References}

1. Weichselbaum RR, Hellman S. Oligometastases revisited. Nat Rev Clin Oncol. 2011;8(6):378. doi:10.1038/nrclinonc.2011.44

2. Correa RJ, Salama JK, Milano MT, Palma DA. Stereotactic body radiotherapy for oligometastasis: opportunities for biology to guide clinical management. Cancer J. 2016;22(4):247-256. doi:10.1097/ PPO.0000000000000202

3. Timmerman RD, Bizekis CS, Pass HI, et al. Local surgical, ablative, and radiation treatment of metastases. CA Cancer J Clin. 2009;59 (3):145-170. doi:10.3322/caac.20013

4. Gomez DR, Blumenschein GR, Lee JJ, et al. Local consolidative therapy versus maintenance therapy or observation for patients with oligometastatic non-small-cell lung cancer without progression after first-line systemic therapy: a multicentre, randomised, controlled, Phase 2 study. Lancet Oncol. 2016;17(12):1672-1682. doi:10.1016/ S1470-2045(16)30532-0

5. Heimbach JK, Kulik LM, Finn RS, et al. AASLD guidelines for the treatment of hepatocellular carcinoma. Hepatology. 2018;67 (1):358-380. doi:10.1002/hep.29086

6. European Association for the Study of the Liver. Electronic address eee, European Association for the Study of the L. EASL Clinical Practice Guidelines: management of hepatocellular carcinoma. J Hepatol. 2018;69(1):182-236.

7. Natsuizaka M, Omura T, Akaike T, et al. Clinical features of hepatocellular carcinoma with extrahepatic metastases. $J$ Gastroenterol Hepatol. 2005;20(11):1781-1787. doi:10.1111/j.1440-1746.200 5.03919.x

8. Yang Y, Nagano $\mathrm{H}$, Ota $\mathrm{H}$, et al. Patterns and clinicopathologic features of extrahepatic recurrence of hepatocellular carcinoma after curative resection. Surgery. 2007;141(2):196-202. doi:10.1016/j. surg.2006.06.033

9. Therasse P, Arbuck SG, Eisenhauer EA, et al. New guidelines to evaluate the response to treatment in solid tumors. J Natl Cancer Inst. 2000;92(3):205-216. doi:10.1093/jnci/92.3.205

10. Lencioni R, Llovet JM Modified RECIST (mRECIST) assessment for hepatocellular carcinoma. Paper presented at: Seminars in liver disease 2010 .

11. Health U, Services H. National Cancer Institute common terminology criteria for adverse events (CTCAE) Version 4.03, June 14, 2010. 2018.

12. Ho DE, Imai K, King G, Stuart EA. MatchIt: nonparametric preprocessing for parametric causal inference. J Statistical Software. 2011;42. doi:10.18637/jss.v042.i08

13. Zhu M, Jiang Y, Yang Y. Clinical application of isolated pulmonary metastasectomy for primary hepatocellular carcinoma postoperative. $J$ Med Res. 2013;42(5):117-119.

14. Chen F, Sato K, Fujinaga T, et al. Pulmonary resection for metastases from hepatocellular carcinoma. World $J$ Surg. 2008;32 (10):2213-2217. doi:10.1007/s00268-008-9684-8

15. Tomimaru Y, Sasaki Y, Yamada T, et al. The significance of surgical resection for pulmonary metastasis from hepatocellular carcinoma. Am J Surgery. 2006;192(1):46-51. doi:10.1016/j.amjsurg.20 05.12.006

16. Lam C, Lo C, Yuen W, Liu C, Fan S. Prolonged survival in selected patients following surgical resection for pulmonary metastasis from hepatocellular carcinoma. British J Surgery. 1998;85(9):1198-1200. doi:10.1046/j.1365-2168.1998.00846.x

17. Kobayashi S, Takahashi S, Kato Y, et al. Surgical treatment of lymph node metastases from hepatocellular carcinoma. $J$ Hepatobiliary Pancreat Sci. 2011;18(4):559-566. doi:10.1007/s00534-011-0372-y

18. Park JS, Yoon DS, Kim KS, et al. What is the best treatment modality for adrenal metastasis from hepatocellular carcinoma? J Surg Oncol. 2007;96(1):32-36. doi:10.1002/jso.20773 
19. Weichselbaum RR. The 46th David A. Karnofsky Memorial Award lecture: oligometastasis - from conception to treatment. J Clin Oncol. 2018;36(32):3240-3250. doi:10.1200/JCO.18.00847

20. Massaut E, Bohlok A, Lucidi V, Hendlisz A, Klastersky JA, Donckier V. The concept of oligometastases in colorectal cancer: from the clinical evidences to new therapeutic strategies. Curr Opin Oncol. 2018;30(4):262-268. doi:10.1097/CCO.0000000000000453

21. Kim C, Hoang CD, Kesarwala AH, Schrump DS, Guha U, Rajan A. Role of local ablative therapy in patients with oligometastatic and oligoprogressive non-small cell lung cancer. J Thoracic Oncol. 2017;12(2):179-193. doi:10.1016/j.jtho.2016.10.012

22. Abdel-Rahman O. Role of liver-directed local tumor therapy in the management of hepatocellular carcinoma with extrahepatic metastases: a SEER database analysis. Expert Rev Gastroenterol Hepatol. 2017;11(2):183-189. doi:10.1080/17474124.2017.1259563

23. Kim J, Sinn D-H, Choi MS, et al. Hepatocellular carcinoma with extrahepatic metastasis: are there still candidates for transarterial chemoembolization as an initial treatment? PLoS One. 2019;14:3.

24. Hu Z, Huang P, Zhou Z, et al. Aggressive intrahepatic therapies for synchronous hepatocellular carcinoma with pulmonary metastasis. Clin Transl Oncol. 2018;20(6):729-739. doi:10.1007/s12094-017-1779-y

25. Uchino K, Tateishi R, Shiina S, et al. Hepatocellular carcinoma with extrahepatic metastasis: clinical features and prognostic factors. Cancer. 2011;117(19):4475-4483. doi:10.1002/cncr.25960

26. Aino H, Sumie S, Niizeki T, et al. Clinical characteristics and prognostic factors for advanced hepatocellular carcinoma with extrahepatic metastasis. Mol clin oncol. 2014;2(3):393-398. doi:10.3892/ mco.2014.259

27. Hakeem A, Young R, Marangoni G, Lodge J, Prasad K. Systematic review: the prognostic role of alpha-fetoprotein following liver transplantation for hepatocellular carcinoma. Aliment Pharmacol Ther. 2012;35(9):987-999.
28. Merani S, Majno P, Kneteman NM, et al. The impact of waiting list alpha-fetoprotein changes on the outcome of liver transplant for hepatocellular carcinoma. $J$ Hepatol. 2011;55(4):814-819. doi:10.1016/j.jhep.2010.12.040

29. Yang SH, Suh K-S, Lee HW, et al. A revised scoring system utilizing serum alpha-fetoprotein levels to expand candidates for living donor transplantation in hepatocellular carcinoma. Surgery. 2007;141 (5):598-609. doi:10.1016/j.surg.2006.11.006

30. Sotiropoulos GC, Lang H, Nadalin S, et al. Liver transplantation for hepatocellular carcinoma: university Hospital Essen experience and metaanalysis of prognostic factors. J Am Coll Surg. 2007;205 (5):661-675. doi:10.1016/j.jamcollsurg.2007.05.023

31. Wang ZX, Song SH, Teng F, et al. A single-center retrospective analysis of liver transplantation on 255 patients with hepatocellular carcinoma. Clin Transplant. 2010;24(6):752-757. doi:10.1111/ j.1399-0012.2009.01172.x

32. Fujiki M, Takada Y, Ogura Y, et al. Significance of des-gammacarboxy prothrombin in selection criteria for living donor liver transplantation for hepatocellular carcinoma. Am J Transpl. 2009;9 (10):2362-2371. doi:10.1111/j.1600-6143.2009.02783.x

33. Perez-Saborido B, de Los Galanes SJ, Menéu-Díaz J, et al. Tumor recurrence after liver transplantation for hepatocellular carcinoma: recurrence pathway and prognostic factors. Paper presented at: Transplantation proceedings 2007.

34. Lassandro G, Picchi SG, Bianco A, et al. Effectiveness and safety in radiofrequency ablation of pulmonary metastases from HCC: a five years study. Med Oncol. 2020;37(4):1-7. doi:10.1007/s12032-02001352-2
Journal of Hepatocellular Carcinoma

\section{Publish your work in this journal}

The Journal of Hepatocellular Carcinoma is an international, peerreviewed, open access journal that offers a platform for the dissemination and study of clinical, translational and basic research findings in this rapidly developing field. Development in areas including, but not limited to, epidemiology, vaccination, hepatitis therapy, pathology

\section{Dovepress}

and molecular tumor classification and prognostication are al considered for publication. The manuscript management system is completely online and includes a very quick and fair peer-review system, which is all easy to use. Visit http://www.dovepress.com/ testimonials.php to read real quotes from published authors. 